\title{
GÉNERO
}

\section{Violencia en puérperas asociada a sus creencias sobre autonomía y derechos sexuales}

\author{
Carmen Marina Arrom Suhurt ${ }^{1}$, María Auxiliadora Arrom Suhurt ${ }^{1}$, \\ María del Pilar Fresco², Cristina Haydée Arrom Suhurt ${ }^{1}{ }^{2}$, María \\ Mónica Ruoti ${ }^{1}$, Marcos Capurro ${ }^{3}$
}

\section{Resumen}

Introducción: Las normas sociales y culturales tradicionales de género con frecuencia hacen a las mujeres más vulnerables a la violencia infligida por la pareja. Introducción: las normas sociales y culturales tradicionales de género con frecuencia hacen a las mujeres más vulnerables a la violencia infligida por la pareja.

Objetivo: Se buscó asociar las creencias sobre autonomía y derechos sexuales con violencia en puérperas víctimas.

Material y Método: Investigación retrospectiva, con fuentes secundarias y muestreo consecutivo. 304 puérperas fueron entrevistadas en un hospital público con un cuestionario estructurado que contenía características sociodemográficas, la Escala de Gelles y Straus para medir diferentes formas de violencia y un listado de 11 dichos populares. Se utilizó estadística descriptiva y analítica para el análisis de la información.

Resultados: 32,3\% (99) fue víctima de violencia Psicológica; 9,2\% (28) de violencia física; 9,2\% (28) abuso sexual. Se encontró una correlación $(p<0,000)$ entre víctimas de violencia psicológica y quienes portaban creencias en Quien te quiere te aporrea y $(p<0,039)$ Si a una mujer el marido le golpea, por algo será. Correlación $(p<0,000)$ entre víctimas de violencia física y acuerdos con Quien te quiere te aporrea y $(p<0,035)$ Si a una mujer el marido le golpea, por algo será, entre otros.

Conclusiones: Mayoría estuvo de acuerdo con dichos sobre autonomía de la mujer y derechos sexuales y en desacuerdo con aquellos de violencia de género. Finalmente es de destacar la asociación significativa entre una minoría de puérperas, víctimas de violencia de diferentes formas, que estaba en desacuerdo con la autonomía y derechos sexuales y de acuerdo con expresiones que legitiman violencia de género. Las correlaciones encontradas ponen de

\footnotetext{
1. Centro para el Desarrollo de la Investigación Científica (CEDIC).

2. Cátedra de Psiquiatría de la Universidad Nacional de Asunción (UNA).

3. Centro Nacional de Control de Adicciones.

E-mail: maryarrom@yahoo.com.ar

DOI: 10.26885/rcei.foro.2018.94
} 
manifiesto que, la exposición como víctima de violencia física y psicológica durante la infancia, ha posibilitado la legitimación de la violencia de género a través de las creencias en el grupo de estudio y de la misma forma entender como natural el solucionar conflictos e interactuar en la cotidianeidad utilizando la violencia física y psicológica, aceptando la utilización de golpes, gritos y amenazas en las relaciones de pareja (Moragas Mereles, 2015; González Vera, 2015). La violencia de pareja y la violencia sexual producen a las víctimas y a sus hijos graves problemas físicos, psicológicos, sexuales y reproductivos a corto y a largo plazo, y tienen un elevado costo económico y social que repercuten en toda la sociedad (OMS 2016; González Vera, 2013; González Vera, 2012). Las mujeres podrían quedar aisladas e incapacitadas en lo laboral, abandonar actividades cotidianas y verse debilitadas para cuidar de sí mismas y de sus hijos (OMS, 2016; ONU-MUJERES-PNUD, 2015; Moragas Mereles, 2014). El ser agresor o víctima se potencia al haber sufrido maltrato durante la infancia y aumentan las probabilidades de trasladar dicha violencia a hijos e hijas (Gómez López, 2013).

Palabras clave: creencias, violencia género, autonomía, derechos sexuales y reproductivos, mujeres puérperas.

\section{RefERENCIAS}

Arrom, C. M., Fresco, M. P., Arrom, M. A., Arrom, C. (2015). Afirmaciones y creencias sobre violencia de género y autonomía de la mujer en población consultante. Estudio comparativo. Revista Científica Estudios e Investigaciones, 4(1), p. 9-20.

Arrom, C., Ruoti, M., Samudio, M., Orué, E., Arrom, C. M. (2015). Sintomatología depresiva en embarazadas víctimas de abuso sexual. Mem. Inst. Investig. Cienc. Salud, 13(3), p. 82-87

Barboza, L., Martínez, T. (2001). Compendio... Niñez. Marco Normativo de los Derechos de la Niñez y la Adolescencia. Asunción: Fondo de las Naciones Unidas para la Infancia (UNICEF), Coordinadora por los Derechos de la Infancia y la Adolescencia (CDIA).

Bosch-Fiol, E., Ferrer-Pérez, V. (2012). Nuevo mapa de los mitos sobre la violencia de género en el siglo XXI. Psicothema, 24(4), p. 548-554.

Castro, R., Ruíz, A. (2004). Prevalencia y severidad de la violencia contra mujeres embarazadas, México. Rev Saúde Pública, 38(1), 62-70. 